\title{
Cycloaliphatic epoxy-based hybrid nanocomposites reinforced with POSS or nanosilica for improved environmental stability in low Earth orbit.
}

\author{
Agnieszka Suliga $^{\mathrm{a}}$, Ian Hamerton ${ }^{\mathrm{b}}$, Andrew Viquerat ${ }^{\mathrm{a}}$ \\ ${ }^{a}$ Univeristy of Surrey, Department of Mechanical Engineering Sciences, Faculity of Engineering and Physical \\ Sciences, Guildford, GU2 7XH, UK \\ ${ }^{b}$ University of Bristol, Advanced Composites Centre for Innovation and Science (ACCIS), Department of \\ Aerospace Engineering, Bristol, BS8 1TR, UK
}

\begin{abstract}
The purpose of this study is to demonstrate the properties of novel nanocomposites, based on cycloaliphatic epoxy resin additionally reinforced with silicon-containing nanostructures (monoor octa-functional POSS or nanosilica). The changes in properties are discussed for the varied combinations of cycloaliphatic epoxy with a curing agent (cycloaliphatic amine or anhydride) and the nanomodifier. The influence of modification on thermal stability, curing behaviour, morphology, surface chemistry, and topography were studied with TGA, DSC, ATR-FTIR, XPS and LCM. The results show that when POSS and/or nanosilica are incorporated to the cycloaliphatic matrix they influence curing behaviour and glass transition temperatures $\left(\mathrm{T}_{g}\right)$, where mono-POSS increases $\mathrm{T}_{g}$ and octa-POSS decreases it with respect to nanosilica. Mono-POSS produces silicon-rich surfaces but tends to agglomerate and increase surface roughness. Octa-POSS and nanosilica penetrate the polymer matrix more deeply and disperse more easily. From the selected modifiers, octa-POSS shows the highest thermal stability.

Keywords: Cycloaliphatic epoxy, Nanosilica, Polymer matrix composites, POSS, Environmental stability

Cycloaliphatic epoxy resins offer an improved environmental resistance in comparison with standard Bisphenol A or Bisphenol $\mathrm{F}$ diglycidyl ether epoxies (DGEBA and DGEBF) [1]. This is due to the absence of strongly UV absorbent chromophoric groups, such as unsaturated aromatic
\end{abstract}

\footnotetext{
*Corresponding author: a.viquerat@surrey.ac.uk
} 
rings, which are found in DGEBA-like epoxies. Cycloaliphatic resins comprise fully saturated, nonaromatic rings which makes them better suited for applications requiring resistance to ultraviolet degradation. Thus, cycloaliphatic epoxy resins are used in outdoor applications such as electrical insulators, but also in the field of protective coatings due to their low viscosity and good adhesion properties. Additionally, anhydride-cured resins systems show reduced moisture absorption, since hydroxyl groups are not generated during the ring opening reactions as in case of amine-cured systems.

Recently, the use of carbon fibre reinforced epoxy structures have been observed in very demanding applications, for instance in a low Earth orbit where the material is exposed to highly energetic UV radiation, oxidation due to residual atmosphere (atomic oxygen erosion) or constant thermal cycling [2, 3, 4]. For structural applications usually highly aromatic epoxy resins, such as DGEBA or TGDDM are used due to their high stiffness provided by the rigid ring skeletons, however, the high aromatic content makes them vulnerable to ultraviolet degradation. Additionally, in applications which involve temperature and the oxygen atmosphere, the thermal-oxidative resistance of DGEBA-like epoxies is compromised [5, 6].

Epoxy resins are very prone to degradation in space [7, 8] and in order to improve their environmental resistance, research has been focused on the development of epoxy resin nanocomposites, reinforced with an inorganic phase which is less susceptible to weather-induced degradation [9, 10]. One of the most common inorganic additives to epoxy resins is nanosilica, a filler that contributes to better weather-stability and improved thermo-mechanical properties [11, 12, 13, 14, 15. Recently, a new class of hybrid silicon-containing materials were introduced as modifiers for epoxy resins. In 25 particular, polyhedral oligomeric silsesquioxanes (POSS) have gained attention due to the fact that they possess both organic and inorganic character and can be functionalised with a various number of reactive moieties. Previous research findings prove that addition of POSS to epoxy resin blends dramatically reduces water uptake [16], improves resistance to thermo-oxygen degradation [17], thermal stability and fire retardancy [18, 19] and also such materials show remarkable resistance to atomic oxygen, which is critical for extraterrestrial exposures [20].

The epoxy system studied here is an organic-inorganic hybrid developed primary for protection of ultra-thin CFRP structures in the environment of low Earth orbit (Fig. 1). In this work we present a concept inspired by sandwich panels [21, that are constructed from two different materials, one on the outside and one on the inside, each providing a specific set of properties to the structure. By 
applying the cycloaliphatic epoxy resin system reinforced with silicon nanoparticles on the outer faces, the structure is prepared to tolerate the harsh environment, maintaining its high stiffness and flexibility provided by the core, highly aromatic epoxy resin and is able to carry shear stresses and withstand buckling. Two types of silicon nanoparticles were considered and blended with the cycloaliphatic epoxy resin; POSS nanocages which are expected to form chemical bonds with polymer matrices and nanosilica, which should acts like a physical reinforcing agent.

POSS-reinforced epoxy resins have been investigated in the past, however, the main focus of this investigation was on aromatic epoxy resins such as DGEBA 22, 23, 24, 25, 26, while the modification of the family of cycloaliphatic epoxy resins remains relatively unexplored. The goal of this work is to characterize the properties of novel cycloaliphatic epoxy POSS/silica blends and compare the performance of this new class of hybrid modifiers (drawn from the POSS family) with more common, commercial nanosilica. The motivation for using cycloaliphatic epoxy resin reinforced with silicon nanoparticles for space application originates from previous work in which researchers proved the higher UV resistance of this epoxy type [1, 27] and remarkable endurance to atomic oxygen of polymers reinforced with POSS 28] or various other nanoadditives such as $\mathrm{ZnO}_{2}$ 229, $\mathrm{Al}_{2} \mathrm{O}_{3}$ [30] or nanotubes 31]. It was observed in case of silicon derivatives that the chemical affinity of silicon towards the oxygen results in formation of silica protective layer on the polymeric surfaces, which significantly deceases the rate of degradation with time [28, 32. For this reason, silicon derivatives have been selected for this work.

The findings of this study can help to develop an epoxy resin system that could be used in a form of a protective coating or a composite matrix for better performance and prolonged longevity of CFRP structures subjected to operation in the hazardous environments, such as in low Earth orbit.

\section{Experimental}

\subsection{Materials}

All materials used in this study are commercially available and were used as received, without further purification. The cycloaliphatic epoxy resins, CY 179 (bis-(epoxycyclohexyl)-methylcarboxylate) and CY 184 (cyclohexane-1,2-dicarboxylate) denoted further as CY-1 and CY-2, respectively were obtained from Huntsman. Selected curing agents included cycloaliphatic amine (Aradur 2954) and 


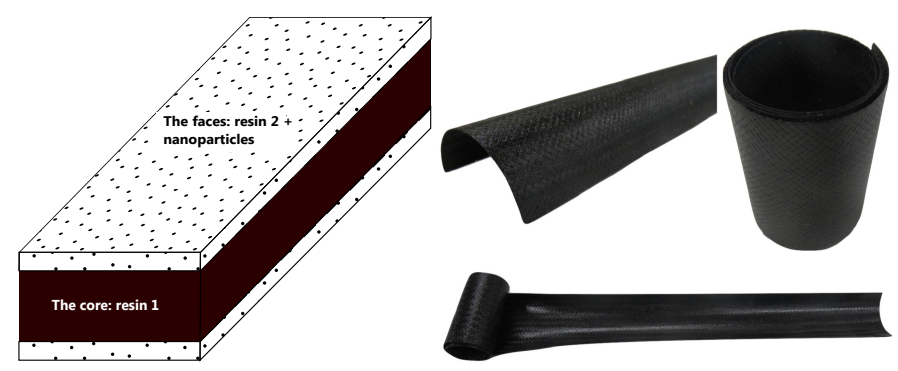

Figure 1: The concept of a hybrid, dual resin CFRP structure - core material providing structural properties and the outer layers environmental protection.

anhydride (Aradur $917 \mathrm{CH}$ ) used with an accelerator (1-methylimidazole, DY070) to initiate the reaction and were also obtained from Huntsman.

Epoxy-POSS, mono-funtional (EP0402-Epoxycyclohexyllsobutyl, in powder form) and octafunctional (EP0409 Glycidyl POSS, a viscous liquid) bearing one and eight reactive epoxide groups, respectively, were both obtained from Hybrid Plastics (Hattiesburg, USA). The nanosilica powder (10-20 nm) was purchased from Sigma Aldrich. The structures of the cycloaliphatic resins, curing agents and POSS reagents used in this study are presented in the Fig. 2

\subsection{Preparation of specimens}

Each resin system: CY-1/Anhydride and CY-2/Amine was modified with 5wt\% nanoparticles since it was reported in literature that usually POSS loadings up to 10wt\% are beneficial [33, 19. Mono-, octa-POSS or nanosilica were used as additives, so in total six combinations were prepared. To achieve a good level of dispersion, the modifiers were initially pre-mixed with the curing agents in 5:95 weight ratio and sonicated in an ultrasonic bath for minimum of $1 \mathrm{~h}$ at room temperature (RT). After this time, resins were added and the sonication step was repeated. Curing was performed in a heating oven, following a cycle: heating from $\mathrm{RT}$ to $90^{\circ} \mathrm{C}$ with a ramp of $3{ }^{\circ} \mathrm{C}$ per minute and dwelling for $45 \mathrm{~min}$, then heating up to $180^{\circ} \mathrm{C}$ with the same ramp rate and dwelling for $2 \mathrm{~h}$. The heating cycle depended on the character of the core epoxy resin, which was a one part epoxy resin film (MTM44-1) supplied by Cytec-Solvay (Wilton, UK). 


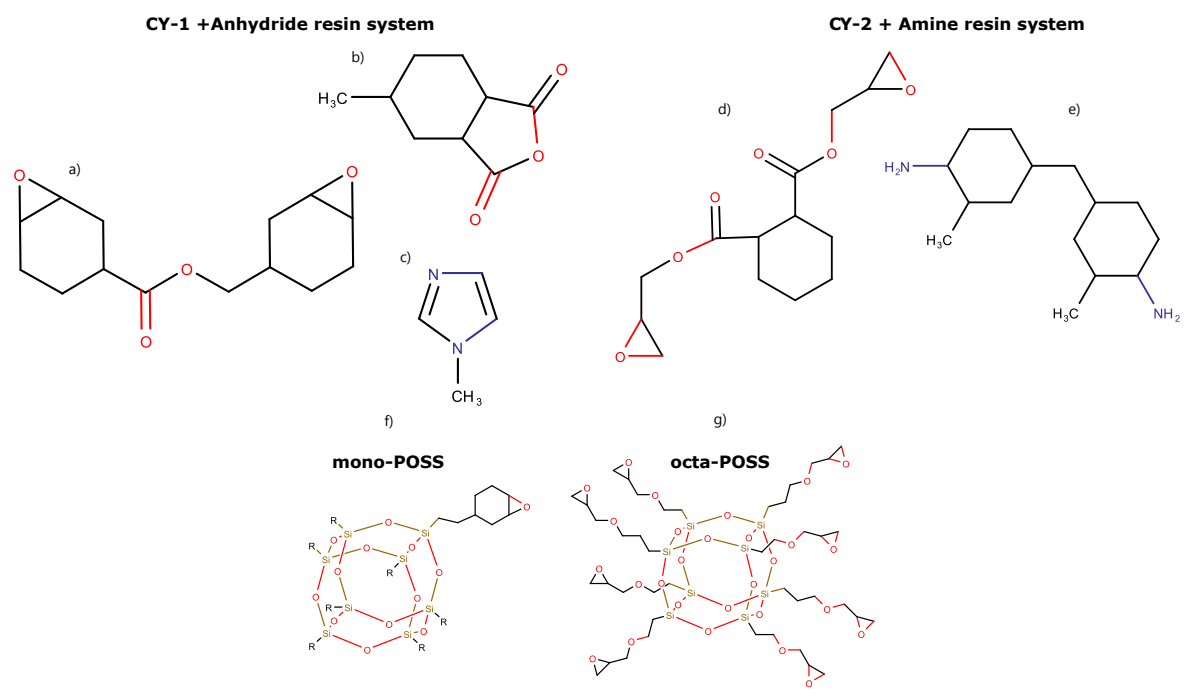

Figure 2: Chemical structures of materials used in this study.

\section{Characterization}

Fourier transform infra-red spectroscopy in Attenuated total reflection mode (ATR-FTIR). The chemical structure and degree of curing were characterized by ATR-FTIR spectroscopy, using an Agilent Cary600 spectrometer, 32 scans per sample, at the resolution of $4 \mathrm{~cm}^{-1}$ in absorbance mode. Spectra were acquired in the region $600-3800 \mathrm{~cm}^{-1}$ at RT.

Differential scanning calorimetry (DSC). DSC was performed on the uncured blends, using a TA Instruments Q1000 running a TA Universal Analysis 2000 software, under a $50 \mathrm{ml} / \mathrm{min}$ nitrogen flow. Hermetically sealed aluminum pans, containing samples of approximately 6-6.5 mg, were subjected to a heat/cool/heat analysis. First heating was performed from RT to $300^{\circ} \mathrm{C}$, at a rate of $20^{\circ} \mathrm{C}$ per minute to obtain the curing characteristics. A second heat, with the same heating rate, was used to determine the glass transition temperature from the midpoint of the curve inflection.

Thermogravimetric analysis (TGA). TGA was performed on a TG Instruments apparatus, Q500 on the cured blends. Samples of approximately $8 \mathrm{mg}$ were heated in an open platinum crucible from $\mathrm{RT}$ to $850^{\circ} \mathrm{C}$ with a ramp of $10^{\circ} \mathrm{C}$ per minute in flowing air or nitrogen at $60 \mathrm{ml} / \mathrm{min}$ rate.

Laser scanning confocal microscope (LSM). Surface topography was examined, using a laser scanning confocal microscope (Zeiss, LSM 700), and the topography parameters were obtained using 
ConfoMap Surface Imaging and Analysis Software for ZEISS microscopes. 3D images were obtained with a $10 \times$ objective and the produced scanned area was approximately $3 \times 3 \mathrm{~mm}^{2}$. The average surface roughness was calculated from a minimum of 5 scans.

Scanning electron microscope (SEM) and energy dispersive X-ray spectroscopy (EDX) . Studies of surface morphology and composition were carried out using scanning electron microscope (SEM, JEOL $7100 \mathrm{~F}$ ). Mapping of the silicon distribution over the scanned area was performed using Energy Dispersive X-ray spectroscopy (EDX) on the same SEM apparatus.

$X$-ray photoelectron spectroscopy (XPS). XPS analyses were performed on a ThermoFisher Scientific Instruments (East Grinstead, UK) K-Alpha+ spectrometer. XPS spectra were acquired using a monochromated $\mathrm{Al} \mathrm{K} \alpha$ X-ray source $(\mathrm{h} \nu=1486.6 \mathrm{eV})$. An X-ray spot of $400 \mu \mathrm{m}$ radius was employed. Survey spectra were acquired employing a Pass Energy of $200 \mathrm{eV}$. High resolution, core level spectra for all elements were acquired with a Pass Energy of $50 \mathrm{eV}$. All spectra were charge referenced against the $\mathrm{C} 1 \mathrm{~s}$ peak at $285 \mathrm{eV}$ to correct for charging effects during acquisition. Quantitative surface chemical analyses were calculated from the high resolution, core level spectra following the removal of a non-linear (Shirley) background. The manufacturers Avantage software was used which incorporates the appropriate sensitivity factors and corrects for the electron energy analyser transmission function.

\section{Results and discussion}

\subsection{Curing studies with ATR-FTIR}

To determine the extent to which the cure reactions had progressed, the cycloaliphatic epoxy blends were examined using ATR-FTIR (Fig. 3). Some of the most distinctive signs to confirm the progression of crosslinking reactions in the CY-2/Amine/octa-POSS system are: the increase in the hydroxyl stretching band at around $3300-3600 \mathrm{~cm}^{-1}$, which shows generation of hydroxyl groups following the epoxide ring-opening reaction, the decrease in the epoxide ring breathing band at $915 \mathrm{~cm}^{-1}$ and the decrease in the $3006 \mathrm{~cm}^{-1}$ band assigned to the $\mathrm{C}-\mathrm{H}$ vibration in the strained, three-membered epoxy ring.

In the anhydride curing system, the principal signs of progressing curing reaction can be observed

at $788 \mathrm{~cm}^{-1}$, associated to the opening of an epoxy ring band attached to a cyclohexane ring, and 
the disappearance of bands at 1780 and $1850 \mathrm{~cm}^{-1}$ confirming the reaction between anhydride and epoxy, associated to the asymmetric and symmetric carbonyl stretch of an anhydride ring. There is also an increase in the absorption region (1100-1300 $\mathrm{cm}^{-1}$ ), assigned to coupled ester stretch, which indicates formation of ester linkages between the epoxy and anhydride.

Additional scans were taken after mixing the nanomodifiers with curing agents, but prior to adding the epoxy component, in order to evaluate whether pre-reaction occurs. Obvious signs of prereaction were not detected, probably because the nanomodifiers were added in small concentrations.

ATR-FTIR scans also reveal the presence of Si-O-Si inorganic POSS cages, by a strong absorption band at around $1085 \mathrm{~cm}^{-1}$. Because POSS is added in low concentrations, its absorption within the final blend is relatively low, however it is still detectable. ATR-FTIR is a surface sensitive method, therefore it can be concluded that a silicon-rich surface was produced, which is also confirmed by the XPS analysis.

\subsection{Curing studies and observation of the glass transition shift with DSC}

The influence of adding nano-modifiers to cycloaliphatic epoxies was investigated using dynamic DSC experiments. From the information obtained from the scans, particularly of interest were the observed changes in maximum polymerization temperature and the glass transition temperature (determined from the rescan). Figs. $4 \mathrm{a}$ and $4 \mathrm{c}$ present the curves obtained during the first heating scan. As one may observe changing the configuration of the cycloaliphatic epoxy and replacing the anhydride with an amine, dramatically affects the crosslinking behaviour since the maximum polymerization temperature is strongly dependent on the nature of the curing agent and its reactivity towards the epoxy. In the case of the CY-1/Anhydride resin system it is observed that the material modified with octa-POSS is predictably the most reactive, given the high degree of epoxide functionality. Not only does the polymerization reaction starts at lower temperature, but the peak maximum of the reaction exotherm occurs at $153^{\circ} \mathrm{C}$. The addition of nanosilica apparently exhibits no significant change in the polymerization of epoxy groups compared to the unmodified system and the addition of mono-POSS moves the maximum temperature of polymerization to $172^{\circ} \mathrm{C}$, which indicates that the polymeric chains are restricted and the modifier hinders the polymerization rate. Shifting the polymerization temperature into a higher temperature regime is an indication that the added nano-modifier is hindering the crosslinking reactions and this phenomenon is particularly observed in blends with a tendency to agglomerate. 


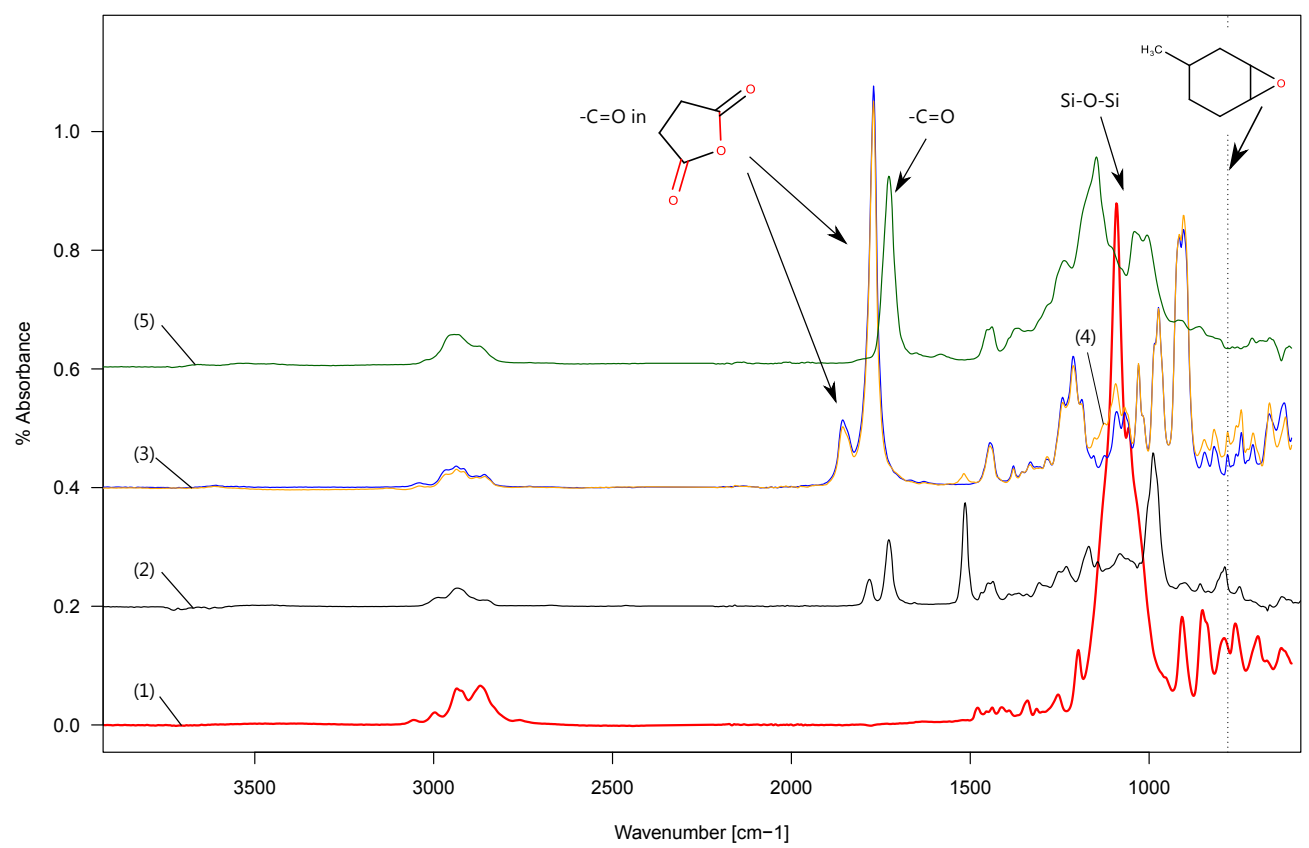

(a) 1-octa-POSS, 2-CY-1 only, 3-anhydride, 4- anhydride/octa-POSS, 5-CY-1/anhydride/octa-POSS cured

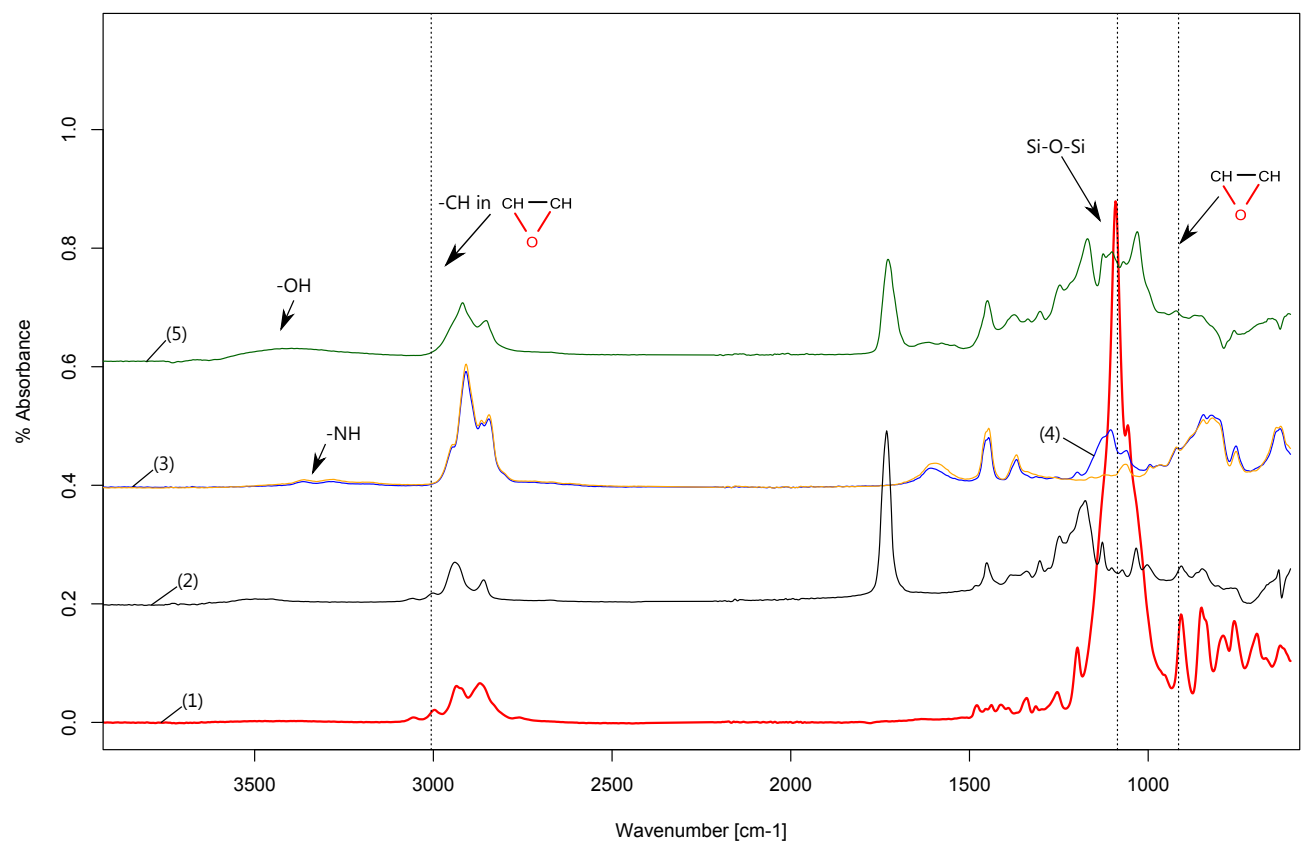

(b) 1-octa-POSS, 2-CY-2 only, 3-amine, 4-amile/octa-POSS, 5-CY-2/amine/octa-POSS cured

Figure 3: FTIR spectra of cycloaliphatic epoxy resin modified with octa-POSS nanoadditive. 
Fig. 5 presents the conversion rates vs. temperature for all cycloaliphatic resin systems. As one may observe, octa-POSS modified systems display the highest reactivity. The biggest influence is observed between CY-1/Anhydride/octa-POSS and CY-1/Anhydride/mono-POSS, as the former apparently achieves the full conversion some $42^{\circ} \mathrm{C}$ sooner than the latter. In case of the CY-2/Amine system which is less chemically compatible than the CY-1/Anhydride, the addition of any type of POSS slows down the reaction rate.

The resin system chemistry and the selected modifier both influence the glass transition of the blend (Table 1, Fig. 4b and 4d . The selection of a curing agent significantly affects the $\mathrm{T}_{g}$ while the nano-modifier only slightly shifts it, depending on whether it acts as a pendant group or a crosslinker. It is expected that a mono-functional POSS will act as a pendant group, behaving as a 'fish-hook' and catching any molecule nearby when the polymer chains are flowing. Indeed, both CY-1/Anhydride and CY-2/Amine resin systems modified with mono-POSS show a slight increase in the value of $\mathrm{T}_{g}$. Octa-POSS modified resins show lower $\mathrm{T}_{g}$, which is probably associated to the fact that those molecules are bigger and act like spacers, decreasing the polymer chains packaging and consequently enabling an easier flow. From the studies of resin systems reactivity, it can be concluded that nanosilica is a better modifier for the CY-1/Anhydride system that it is for CY2/Amine.

Two completely different resin systems had been developed during this study. The CY-1/Anhydride system characterizes of high $\mathrm{T}_{g}$ at about $195^{\circ} \mathrm{C}$, whereas the $\mathrm{CY}-2 /$ Amine system exhibits much lower $\mathrm{T}_{g}$, at about $70-80^{\circ} \mathrm{C}$, depending on the nanomodification. In case of modification with monoand octa-POSS, two glass transitions are visible, which is an indication of phase separation and problems with miscibility level. This behavior might be overcame by much slower curing ramp than $20^{\circ}$ per min during the DSC scan, however it is evident that the compatibility of those systems is lower than in case of the CY-1/Anhydride one that exhibits only one $\mathrm{T}_{g}$. Selecting the system with lower $\mathrm{T}_{g}$ might be beneficial for applications where a structure undergoes thermal cycling, since above $\mathrm{T}_{g}$ the mobility of chain segments is greater, the resin is more flexible and can accommodate for dimensional changes, which might lead to surface cracking in a more brittle, high $\mathrm{T}_{g}$ epoxy.

\subsection{Thermal stability}

Thermal stability of the hybrid cycloaliphatic resins was evaluated with TGA in air and in an inert nitrogen atmosphere. The obtained curves are presented in Fig. 6 and the data is summarized 


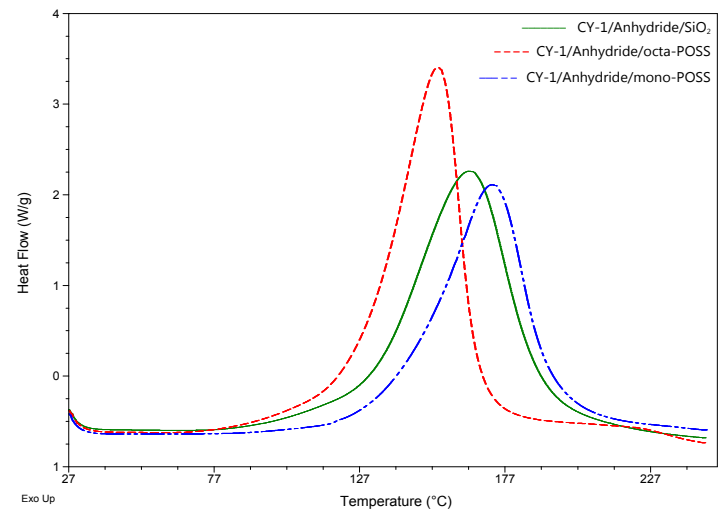

(a) CY-1/Anhydride resin systems - 1st heat

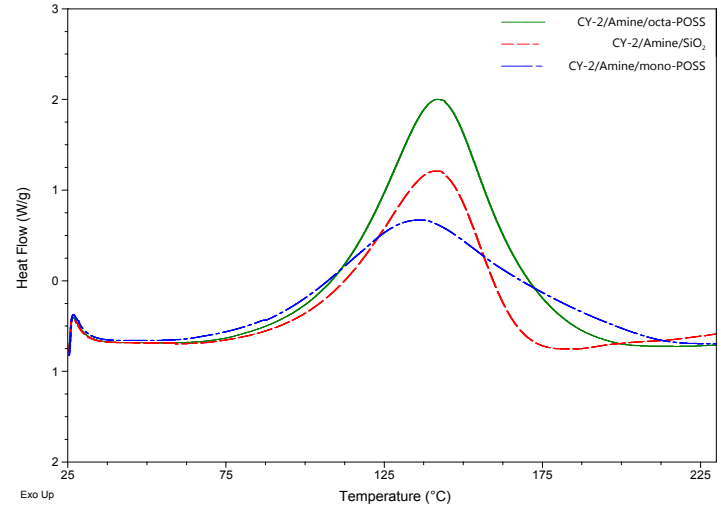

(c) CY-2/Amine resin systems - 1st heat

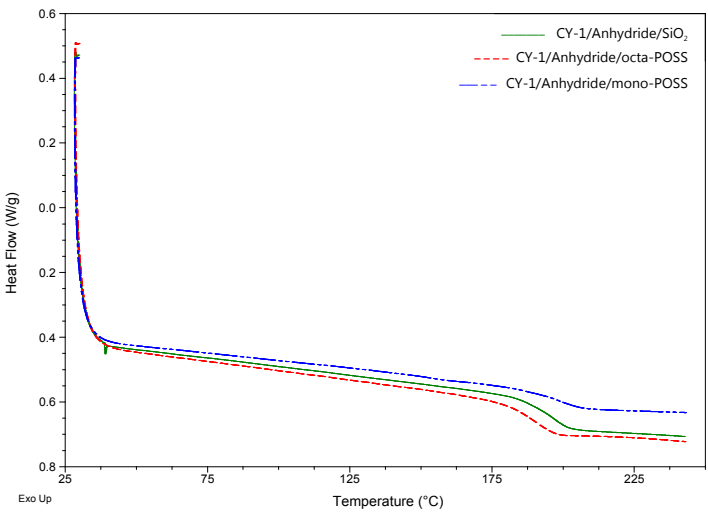

(b) CY-1/Anhydride resin systems - 2nd heat

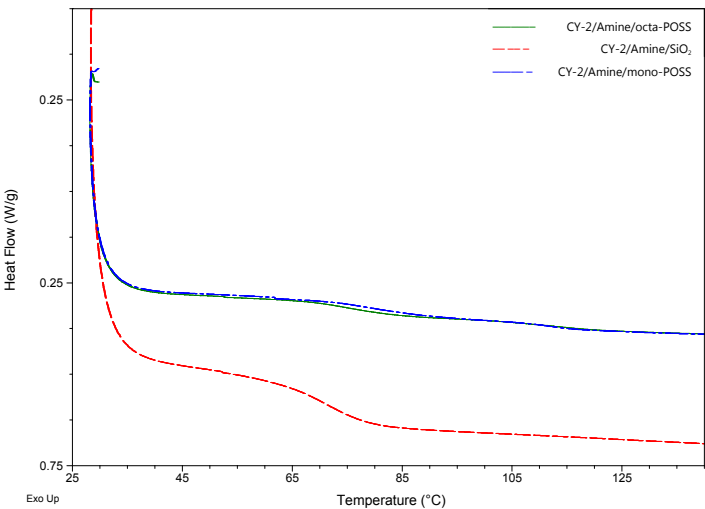

(d) CY-2/Amine resin systems - 2nd heat

Figure 4: DSC curves for cycloaliphatic epoxy resin systems reinforced with silicon nanoparticles.

Table 1: DSC data for the cycloaliphatic epoxy resin systems reinforced with silicon nanoparticles.

\begin{tabular}{|c|c|c|c|}
\hline Sample & $\mathrm{T}_{g}^{*}$ & $\mathrm{~T}_{\max }$ & $\mathrm{E}^{* *}$ \\
\hline $\mathrm{CY}-1 /$ Anhydride $/ \mathrm{SiO}_{2}$ & 194 & 165 & 384 \\
\hline CY-1/Anhydride/mono-POSS & 197 & 172 & 316 \\
\hline CY-1/Anhydride/octa-POSS & 189 & 154 & 349 \\
\hline $\mathrm{CY}-2 /$ Amine $/ \mathrm{SiO}_{2}$ & 71 & 141 & 245 \\
\hline CY-2/Amine/mono-POSS & 80,111 & 137 & 270 \\
\hline CY-2/Amine/octa-POSS & 76,112 & 142 & 376 \\
\hline
\end{tabular}

* Temperature $\left[{ }^{\circ} \mathrm{C}\right] * *$ Enthalpy $[\mathrm{J} / \mathrm{g}]$ 


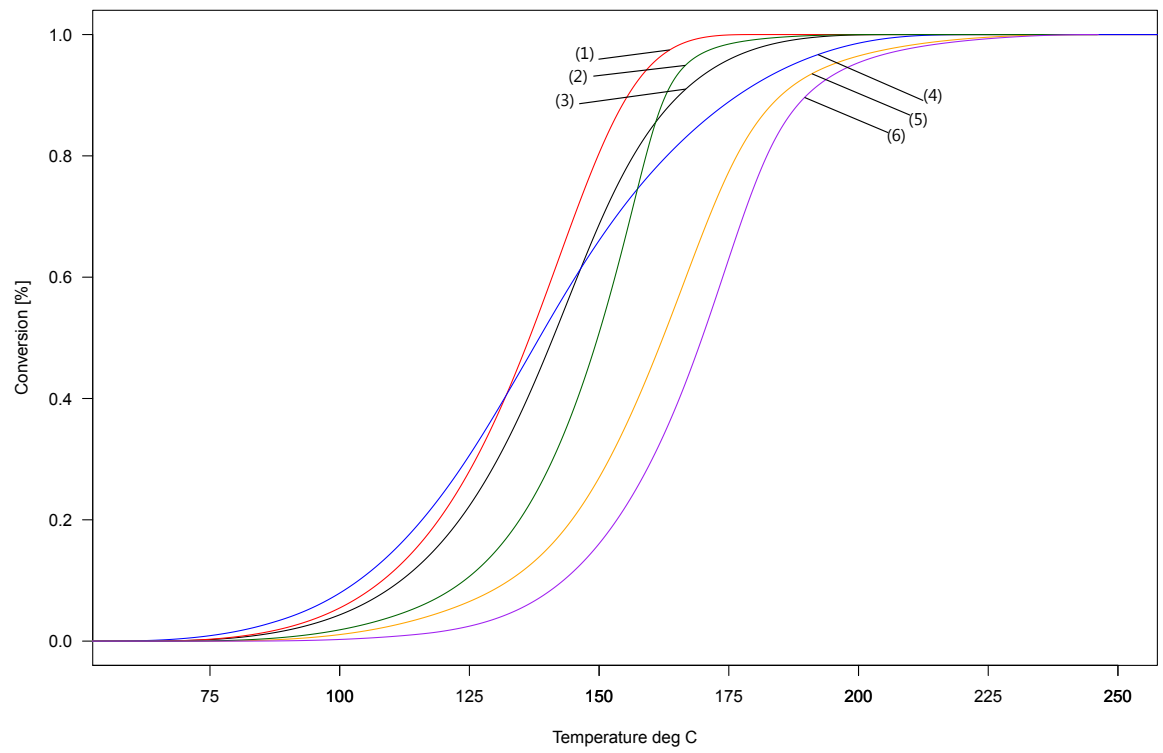

Figure 5: Total conversions vs. temperature: 1-CY-2/Amine/ $\mathrm{SiO}_{2}, \quad 2-\mathrm{CY}-1 /$ Anhydride/octa-POSS, 3-CY2/Amine/octa-POSS, 4-CY-2/Amine/mono-POSS, 5-CY-1/Anhydride/SiO 2 , 6-CY-1/Anhydride/mono-POSS.

in Table 2. In case of the CY-1/Anhydride system, the addition of octa-POSS does not change the thermodegradation pattern with respect to the raw sample, which is an indication of good miscibility. The temperature at which $5 \%$ mass loss occurs $\left(\mathrm{T}_{d 5 \%}\right)$ is shifted $45^{\circ} \mathrm{C}$ higher for this system, which is a very significant improvement. On the other hand, nanosilica and mono-POSS modified samples behave almost identically to one another, but very differently to the raw material, showing three well resolved degradation steps. Such behaviour is probably associated with particle agglomeration and formation of phases which all have different peaks of degradation.

It can be observed that addition of cycloaliphatic nanomodifiers to the CY-2/Amine system has a smaller effect on the degradation characteristics then when added to a CY-1/Anhydride system. CY-2/Amine system degrades in the same fashion in all cases, regardless of the type of silicon nanoparticles, which indicates no significant influence on the thermodegradation mechanism. $\mathrm{T}_{d 5 \%}$ is slightly improved for the system modified with octa-POSS. In the higher temperature regime, the resin system modified with mono-POSS shows the highest mass loss which is probably associated with particle agglomeration. The nanoparticle-rich regions hinder the crosslinking density and make 
Table 2: TGA data for the cycloaliphatic epoxy resin systems reinforced with silicon nanoparticles.

\begin{tabular}{lcccccc} 
& \multicolumn{2}{c}{$\mathrm{T}_{d 5 \%}\left[{ }^{\circ} \mathrm{C}\right]^{*}$} & \multicolumn{2}{c}{$\mathrm{T}_{150{ }^{\circ} \mathrm{C}}[\%]$} & \multicolumn{2}{c}{$\left.\mathrm{T}_{300}{ }^{\circ} \mathrm{C}\right]$} \\
\hline \hline $\mathrm{CY}-1 /$ Anhydride & in air & in $\mathrm{N}_{2}$ & in air & in $\mathrm{N}_{2}$ & in air & in $\mathrm{N}_{2}$ \\
\hline $\mathrm{CY}-1 / \mathrm{Anh} / \mathrm{SiO}_{2}$ & 266 & 265 & 0.4 & 1 & 13.25 & 11.47 \\
\hline $\mathrm{CY}-1 /$ Anh/mono-POSS & 252 & 296 & 1.2 & 0.6 & 14.4 & 5.57 \\
\hline $\mathrm{CY}-1 /$ Anh/octa-POSS & 287 & 271 & 0.6 & 0.9 & 6.95 & 7.7 \\
\hline \hline $\mathrm{CY}-2 /$ Amine & 311 & 311 & 0.8 & 0.8 & 3.05 & 3.8 \\
\hline $\mathrm{CY}-2 /$ Amine/SiO & 259 & 256 & 0.4 & 0.6 & 15.5 & 15.4 \\
\hline $\mathrm{CY}-2 /$ Amine/mono-POSS & 260 & 266 & 0.9 & 0.7 & 18.4 & 18 \\
\hline $\mathrm{CY}-2 /$ Amine/octa-POSS & 257 & 255 & 0.8 & 1 & 20.5 & 22 \\
\hline$* \mathrm{~T}_{d 5 \%}$ - temperature at which $5 \%$ mass loss occurs & & & & & &
\end{tabular}

the unreacted parts of the polymer more volatile.

Looking at the mass loss at specific temperatures it is observed that at up to $150^{\circ} \mathrm{C}$, the maximum mass loss of the tested samples is $1.2 \%$. It can be stated that at lower temperatures the effect of the addition of nanoparticles is not evident, however, it is clearly observed at higher temperatures. The effects of nanoparticles on thermodegradation are less apparent in case of the CY-2/Amine system than in the case of CY-1/Anhydride, where in the latter case the resin resistance to elevated temperatures was improved by approximately $33 \%$ using mono-POSS, $52 \%$ using nanosilica and by $77 \%$ using octa-POSS as modifiers.

Looking at all samples reveals that physical modification with nanosilica is less effective than chemical modification with POSS, but the operating temperatures for the structure should determine the selection of POSS or nanosilica.

\subsection{Surface topography and composition}

The developed cycloaliphatic epoxy reinforced with silicon naoparticles were used as a protective coatings on ultra-thin CFRP structures, manufactured from a carbon fibre braid. To establish the surface morphology, 3D profiles were obtained by laser scanning confocal microscope. The surface topography can be seen in Fig. 8. Some surface defects can be noticed, which are introduced during applying the coating and curing the structures into cylindrical shapes. These regions were excluded 


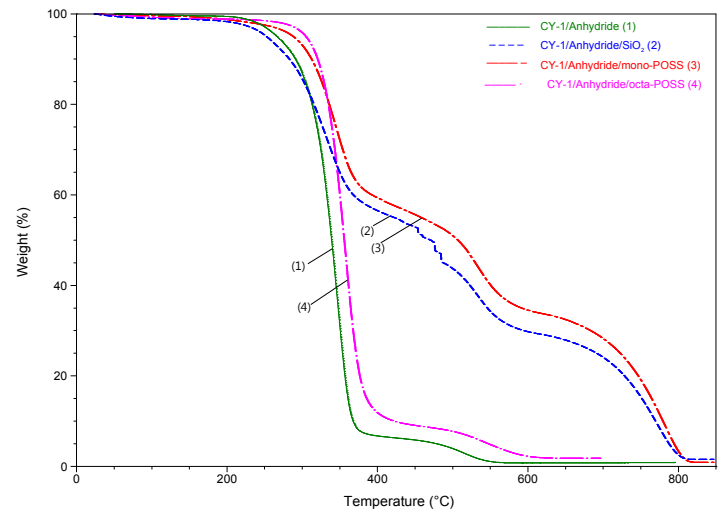

(a) CY-1/Anhydride resin system (1) in air.

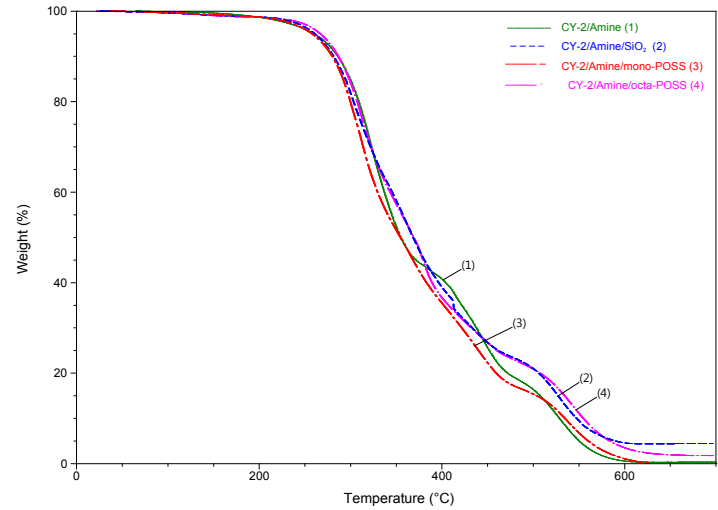

(c) CY-2/Amine resin system (1) in air.

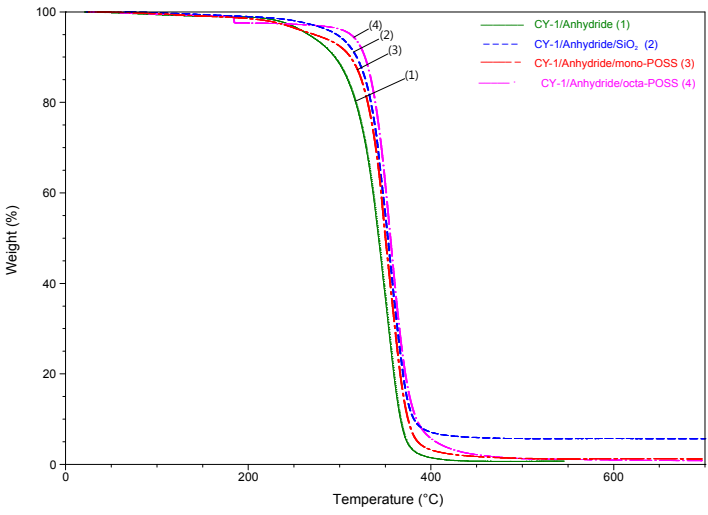

(b) CY-1/Anhydride resin system (1) in $\mathrm{N}_{2}$.

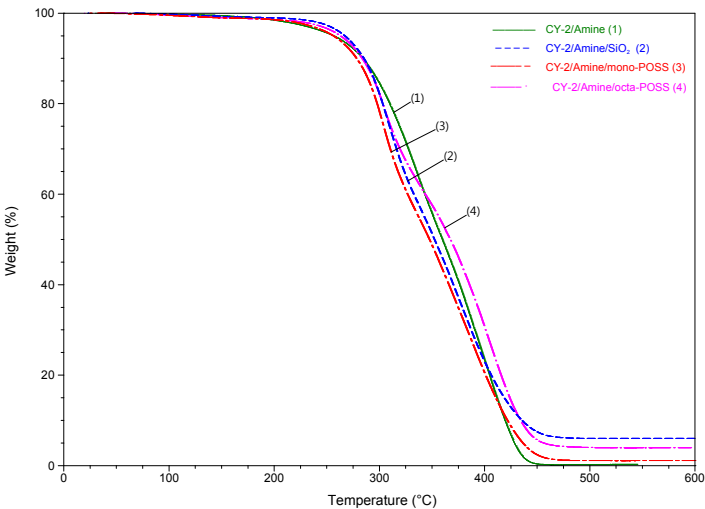

(d) CY-2/Amine resin system (1) in $\mathrm{N}_{2}$.

Figure 6: TGA plots of the cycloaliphatic resin systems reinforced with: 2-SiO 2 , 3-mono-POSS, 4-octa-POSS.

from calculations of surface parameters for consistency.

The average surface roughness $\left(\mathrm{S}_{a}\right)$ is presented in Table 3. Lower $\mathrm{S}_{a}$ values are preferred, since they imply a lower surface area and consequently lower probability of reactions between the surface 
Table 3: Average surface roughness $[\mu \mathrm{m}]$ of cycloaliphatic epoxy resin systems reinforced with silicon nanoparticles.

\begin{tabular}{cccc} 
& $+\mathrm{SiO}_{2}$ & + octa-POSS & + mono-POSS \\
\hline CY-1/Anhydride & 4.57 & 5.35 & 6.64 \\
\hline CY-2/Amine & 4.25 & 4.97 & 8.97 \\
\hline
\end{tabular}

in agreement with other studies [22, 34, 35] and it has also been observed by authors of this work and confirmed by the SEM/EDX analysis. In case of CY-1/Anhydride/mono-POSS, the blend was so incompatible that the additive was visible with a naked eye - an optical image taken with LSM (Fig. 7a) confirms this.

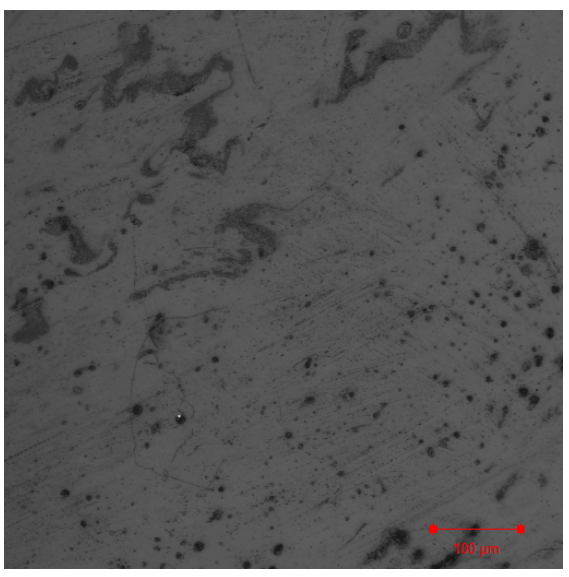

(a) CY-1/Anhydride/mono-POSS

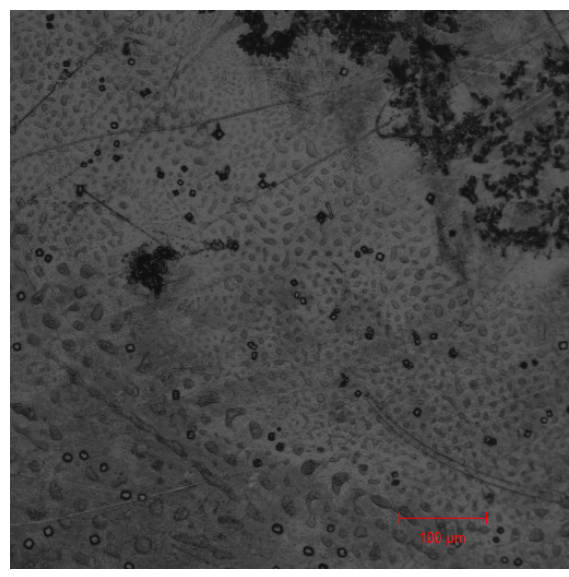

(b) CY-1/Anhydride/octa-POSS

Figure 7: Surface image of the CY-1/Anhydride epoxy resin system obtained with an optical microscope.

Surface elemental composition was evaluated with XPS, which is an useful method to obtain specific surface characteristics. The depth profiles are presented in Fig. 9 and depict the surface content, approximately $5 \mathrm{~nm}$ deep. The most detectable elements were carbon, oxygen and fluorine. The presence of fluorine originates from using PTFE as a release agent during composite manufacturing and this contamination is easily removable by argon sputtering plasma. Silicon nano-modifiers were added in low concentration, therefore there is no silicon abundance on the surface. One can observe that mono-POSS shows much higher concentration than octa-POSS or nanosilica, 7.2 at\% in anhydride and 5.4 at\% in amine-cured resins, which indicates the tendency of mono-POSS to migrate towards the surfaces. On the other hand, nanosilica is hardly detectable on 
of atomic percentage between the CY-1/Anhydride and the CY-2/Amine systems with different nanomodifiers can be seen in Fig. 10 .
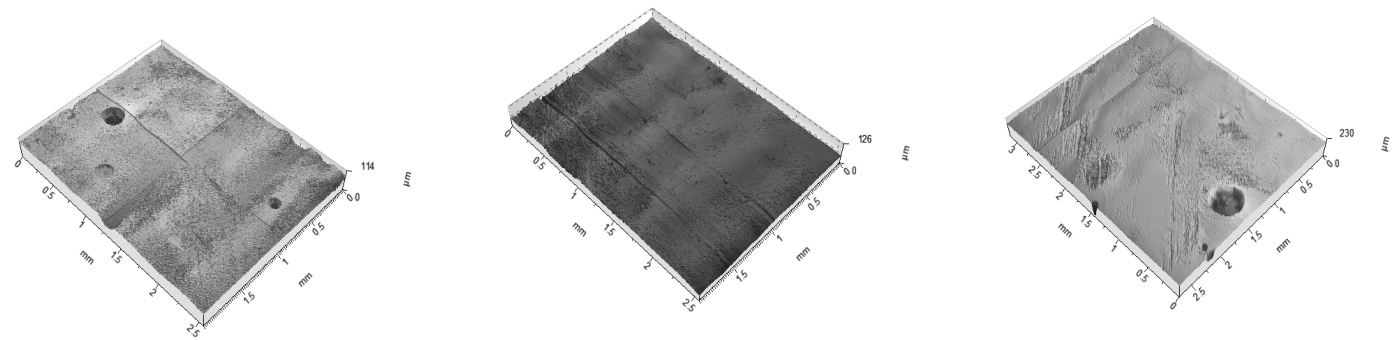

(a) $\mathrm{CY}-1 /$ Anhydride $/ \mathrm{SiO}_{2}$

(b) POSS

CY-1/Anhydride/mono-

(c)

CY-1/Anhydride/octa-

POSS
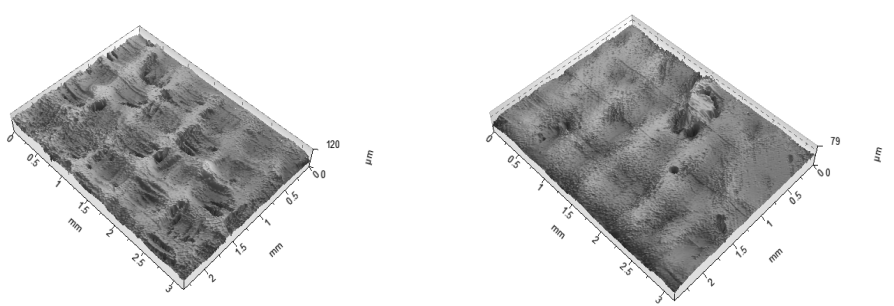

(d) CY-2/Amine/ $/ \mathrm{SiO}_{2}$

(e) CY-2/Amine/mono-POSS (f) CY-2/Amine/octa-POSS

Figure 8: Surface topography of CFRP structures coated with a cycloaliphatic epoxy resins reinforced with either POSS or nanosilica.

\subsection{Surface morphology and dispersion of nanomodifiers}

The problem often encountered in nanocomposites is the agglomeration of nanoparticles which actually leads to deterioration of properties instead of their improvement. Uniform distribution of nanoparticles depends on their compatibility with the host resin system. Previous research revealed that mono-functional POSS reagents tend to agglomerate, due to the comparatively low reactivity and to combat this highly flexible polymers, like polydimethylosiloxane (PDMS), can be added in small quantities, which act like spacers in between the nanoparticles to aid their more even distribution 22 . 

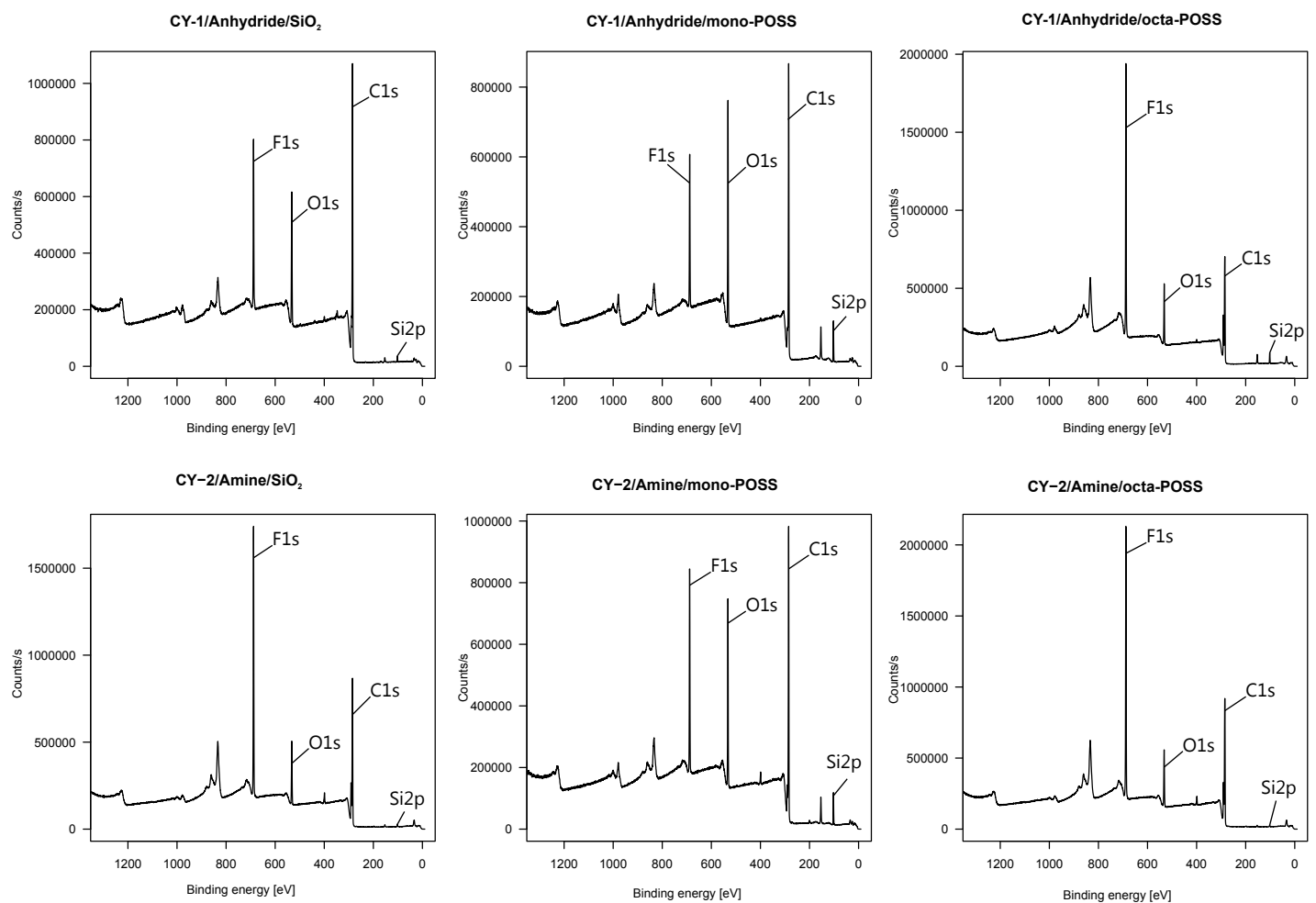

Figure 9: Surface elemental analysis of CFRP structures coated with cycloaliphatic epoxy resins reinforced with POSS or nanosilica.

In the blends of cycloaliphatic resins with POSS, we have observed that mono-functional POSS exhibits tendency to agglomeration, however the octa-functional POSS dispersed homogeneously without addition of spacers, and no agglomerates were visible (Fig. 11. Octa-POSS blends very well with both CY-1/Anhydride and CY-2/Amine systems. On the other hand, the mono-POSS shows good level of blending only with the CY-2/Amine system and in the CY-1/Anhydride large agglomerates are formed during the mixing stage. Nanosilica disperses equally well in both systems, and produces only rare agglomerations about 5-7 $\mu \mathrm{m}$ in size. Nanosilica behaves like a filler, disperses well and does not significantly alter the morphology.

\section{Conclusions}

The aim of this study was to prepare cycloaliphatic epoxy resin nanocomposites reinforced with silicon containing nanoparticles to be used as coatings for improved outdoor resistance and operation 

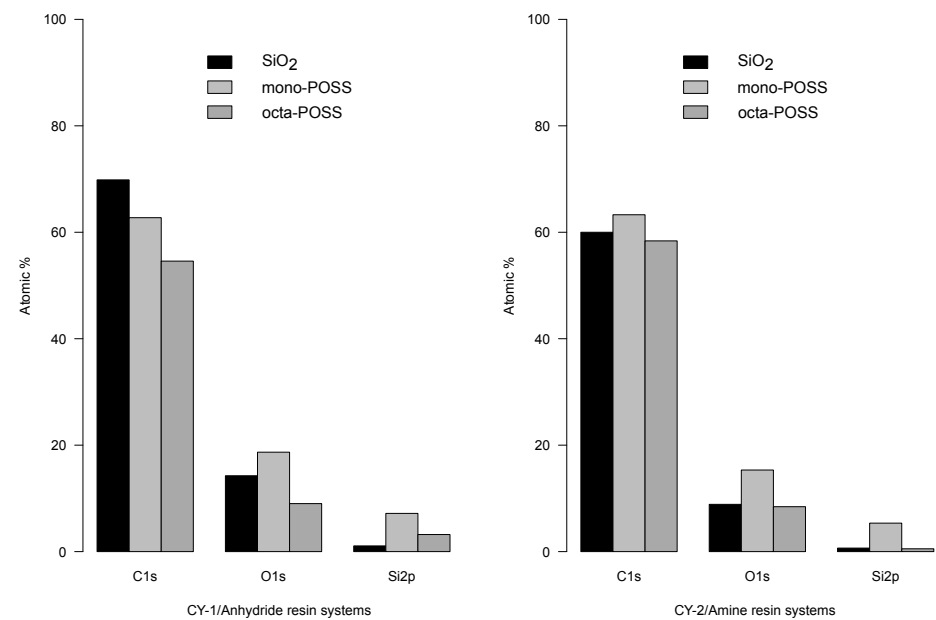

Figure 10: Relative atomic content of carbon, oxygen and silicon on the surfaces of CFRP structures coated with cycloaliphatic epoxy resins reinforced with POSS or nanosilica.

in hostile environments. Two types of cycloaliphatic epoxies (CY-1 and CY-2) were selected and cured either with an anhydride or an amine hardener, respectively. The selected nanomodification included POSS nanocages, with either one (mono-POSS) or eight (octa-POSS) reactive sides or nanosilica powder. ATR-FTIR analysis of modified epoxy shows that cage molecules of POSS have been incorporated to the system and both CY-1/Anhydride and CY-2/Amine resin systems form a crosslinked structure (ATR-FTIR, DSC). DSC data indicates that mono-POSS hinders the reaction rate but increases the $\mathrm{T}_{g}$, while the octa- POSS increases the reaction rate but slightly lowers the $\mathrm{T}_{g}$ with respect to the nanosilica-modified sample.

The combined results from ATR-FTIR, EDX and XPS confirm that silicon is present on the surface, which is important for the environmental protection of the coated structures. Silicon is expected to react with reactive oxygen in formation of silica protective layer, which slows down the erosion rate. In the case of UV and thermal degradation, substituting the C-C and C-N chemical bonds with stronger $\mathrm{Si}-\mathrm{O}, \mathrm{Si}-\mathrm{Si}$ or $\mathrm{Si}-\mathrm{C}$ bonds should also decrease the probability of degradation.

In terms of thermostability, the type of used nanomodifier does not have a significant influence on the thermodegradation mechanism of the CY-2/Amine resin system. Incorporation of mono-POSS and nanosilica to the CY-1/Anhydride resin system results in a change of themodegradation behaviour in respect to the raw sample. Such effect is not observed in the case of 

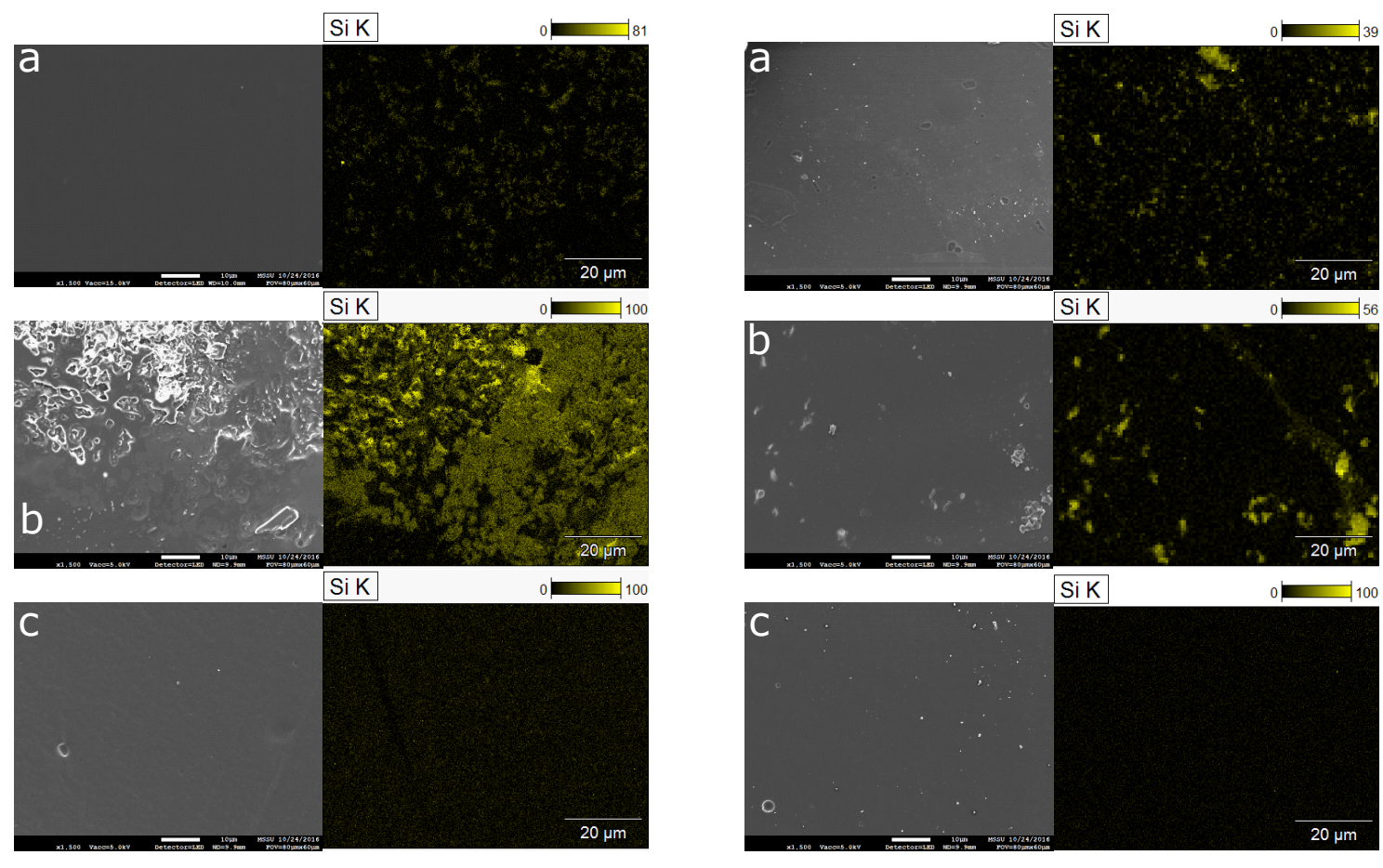

(a) CY-1/Anhydride resin systems reinforced with: ananosilica, b-mono-POSS, c-octa-POSS.

(b) CY-2/Amine resin systems reinforced with: ananosilica, b-mono-POSS, c-octa-POSS.

Figure 11: Morphology and silicon distribution maps of cycloaliphatic epoxy resin systems reinforced with silicon nanoparticles.

CY-1/Anhydride/octa-POSS system which indicates that the material's chemistry is not altered by nanoparticles. Overall, the presence of POSS improves the thermostability (TGA), especially at higher temperatures where the effectiveness of octa-POSS is clearly visible.

The nature of POSS substitutes plays a significant role in the level of compatibility between the POSS nanocages and the polymer matrix. Overall, a satisfactory level of dispersion within the cycloaliphatic epoxy was achieved for nanosilica and octa-POSS and the mono-POSS proved incompatible. The outcomes of this study contribute to the development of epoxy resin systems with higher environmental stability, which can be useful for protection of structures subjected to operation in demanding environments, such as low Earth orbit. 


\section{Acknowledgments}

Financial support from the EPSRC and Rola Tube Technology Ltd in the form of a research

290

\begin{abstract}
The authors should like to thank Huntsman for generous donations of material. Details of the data presented here and how to request access are available from University of Surrey publications repository: (http://epubs.surrey.ac.uk).
\end{abstract}

\section{References} an Epoxy/Amine Resin, 1, Macromolecular Chemistry and Physics 206 (5) (2005) 575-584. doi:10.1002/macp.200400395. URL http://doi.wiley.com/10.1002/macp.200400395 
[6] B. Mailhot, S. Morlat-Thérias, P.-O. Bussiére, J.-L. Gardette, Study of the Degradation of

[12] S. Sprenger, Epoxy resin composites with surface-modified silicon dioxide nanoparticles: A

q [8] J.-H. Han, C.-G. Kim, Low earth orbit space environment simulation and its effects on

[9] L. Peponi, D. Puglia, L. Torre, L. Valentini, J. M. Kenny, Processing of nanostructured polymers and advanced polymeric based nanocomposites, Materials Science and Engineering R: Reports 85 (1) (2014) 1-46. doi:10.1016/j.mser.2014.08.002.

[10] J. Njuguna, K. Pielichowski, Polymer Nanocomposites for Aerospace Applications: Properties, Advanced Engineering Materials 5 (11) (2003) 769-778. doi:10.1002/adem.200310101.

[11] A. Allahverdi, M. Ehsani, H. Janpour, S. Ahmadi, The effect of nanosilica on mechanical, thermal and morphological properties of epoxy coating, Progress in Organic Coatings 75 (4) (2012) 543-548. doi:10.1016/j.porgcoat.2012.05.013.

335 URL http://dx.doi.org/10.1016/j.porgcoat.2012.05.013

\ review, Journal of Applied Polymer Science 130 (3) (2013) 1421-1428. doi:10.1002/app. 39208 .

[13] D.-J. Kwon, P.-S. Shin, J.-H. Kim, Y.-M. Baek, H.-S. Park, K. L. DeVries, J.-M. Park, 340 Interfacial properties and thermal aging of glass fiber/epoxy composites reinforced with a $\quad \mathrm{SiC}$ and $\mathrm{SiO} 2$ nanoparticles, Composites Part B: Engineering 130 (2017) 46-53. doi: 
10.1016/j.compositesb.2017.07.045.

URL http://linkinghub .elsevier . com/retrieve/pii/S1359836816325136

[14] Q. Guo, P. Zhu, G. Li, J. Wen, T. Wang, D. Lu, R. Sun, C. Wong, Study on the effects of interfacial interaction on the rheological and thermal performance of silica nanoparticles

1. reinforced epoxy nanocomposites, Composites Part B: Engineering 116 (2016) 388-397. doi: 10.1016/j.compositesb.2016.10.081.

URL http://dx.doi.org/10.1016/j.compositesb.2016.10.081

[15] J. Abenojar, J. Tutor, Y. Ballesteros, J. del Real, M. Martínez, Erosion-wear, mechanical and thermal properties of silica filled epoxy nanocomposites, Composites Part B: Engineering 120 (2017) 42-53. doi:10.1016/j.compositesb.2017.03.047.

URL http://linkinghub.elsevier . com/retrieve/pii/S1359836816305923

[16] I. Hamerton, W. Tang, J. V. Anguita, S. R. P. Silva, Dramatic reductions in water uptake observed in novel POSS nanocomposites based on anhydride-cured epoxy matrix resins, Materials Today Communications 4 (2015) 186-198. doi:10.1016/j.mtcomm.2015.07.001 URL http://linkinghub.elsevier . com/retrieve/pii/S2352492815300118

[17] Z. Zhang, A. Gu, G. Liang, P. Ren, J. Xie, X. Wang, Thermo-oxygen degradation mechanisms of POSS/epoxy nanocomposites, Polymer Degradation and Stability 92 (11) (2007) 1986-1993. doi:10.1016/j.polymdegradstab.2007.08.004.

360 [18] B. Montero, R. Bellas, C. Ramírez, M. Rico, R. Bouza, Flame retardancy and thermal stability a of organicinorganic hybrid resins based on polyhedral oligomeric silsesquioxanes and montmon rillonite clay, Composites Part B: Engineering 63 (2014) 67-76. doi:10.1016/j.compositesb. 2014.03 .023 .

URL http://www.sciencedirect.com/science/article/pii/S1359836814001395

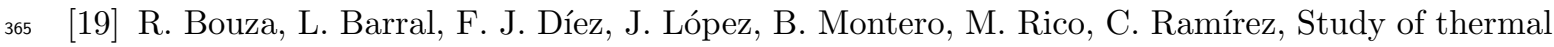
and morphological properties of a hybrid system, iPP/POSS. Effect of flame retardance, Composites Part B: Engineering 58 (2014) 566-572. doi:10.1016/j.compositesb.2013.11.010. URL http://dx.doi.org/10.1016/j.compositesb.2013.11.010 
[20] S. H. Phillips, T. S. Haddad, S. J. Tomczak, Developments in nanoscience: Polyhedral oligomeric silsesquioxane (POSS)-polymers, Current Opinion in Solid State and Materials Science 8 (1) (2004) 21-29. doi:10.1016/j.cossms.2004.03.002.

[21] M. Ashby, Y. Bréchet, Designing hybrid materials, Acta Materialia 51 (19) (2003) 5801-5821. doi:10.1016/S1359-6454(03)00441-5. URL http://linkinghub.elsevier.com/retrieve/pii/S1359645403004415

[22] N. M. Florea, A. Lungu, P. Badica, L. Craciun, M. Enculescu, D. G. Ghita, C. Ionescu, R. G. Zgirian, H. Iovu, Novel nanocomposites based on epoxy resin/epoxy-functionalized polydimethylsiloxane reinforced with POSS, Composites Part B: Engineering 75 (2015) 226-234. doi:10.1016/j.compositesb.2015.01.043 URL http://dx.doi.org/10.1016/j.compositesb.2015.01.043

[23] K. Sethuraman, P. Prabunathan, M. Alagar, Thermo-mechanical and surface properties of POSS reinforced structurally different diamine cured epoxy nanocomposites, RSC Adv. 4 (85) (2014) 45433-45441. doi:10.1039/C4RA06211F. URL http://xlink.rsc.org/?DOI=C4RA06211F

[24] C. H. Su, Y. P. Chiu, C. C. Teng, C. L. Chiang, Preparation, characterization and thermal properties of organic-inorganic composites involving epoxy and polyhedral oligomeric

口 silsesquioxane (POSS), Journal of Polymer Research 17 (5) (2010) 673-681. doi:10.1007/ s10965-009-9355-y.

[25] C. Ramírez, M. Rico, a. Torres, L. Barral, J. López, B. Montero, Epoxy/POSS organicinorganic hybrids: ATR-FTIR and DSC studies, European Polymer Journal 44 (10) (2008) 3035-3045. doi:10.1016/j.eurpolymj.2008.07.024.

[26] Y. Xu, Y. Ma, Y. Deng, C. Yang, J. Chen, L. Dai, Morphology and thermal properties of organic-inorganic hybrid material involving monofunctional-anhydride POSS and epoxy resin,

1. Materials Chemistry and Physics 125 (1-2) (2011) 174-183. doi:10.1016/j.matchemphys. 2010.09 .003

URL http://dx.doi.org/10.1016/j.matchemphys.2010.09.003

[27] J. C. Huang, Y. P. Chu, M. Wei, R. D. Deanin, Comparison of epoxy resins for applications in 
light-emitting diodes, Advances in Polymer Technology 23 (4) (2004) 298-306. doi:10.1002/ adv. 20018.

[28] T. K. Minton, M. E. Wright, S. J. Tomczak, S. A. Marquez, L. Shen, A. L. Brunsvold, R. Cooper, J. Zhang, V. Vij, A. J. Guenthner, B. J. Petteys, Atomic oxygen effects on POSS polyimides in low earth orbit, ACS Applied Materials and Interfaces 4 (2) (2012) 492-502. doi:10.1021/am201509n.

[29] M. Lv, Q. Wang, T. Wang, Y. Liang, Effects of atomic oxygen exposure on the tribological a performance of $\mathrm{ZrO} 2$-reinforced polyimide nanocomposites for low earth orbit space applicati405 ons, Composites Part B: Engineering 77 (2015) 215-222. doi:10.1016/j.compositesb.2015. 03.029

URL http://dx.doi.org/10.1016/j.compositesb.2015.03.029

[30] J.-H. Han, C.-G. Kim, Al2o3 nanotube/epoxy inorganic-organic nanocomposites under simulated leo space environment, in: International Conference on Composite Materials, International Committee on Composite Materials (ICCM) Executive Council (EC), 2005, pp. 69-70.

[31] J.-B. Moon, M.-G. Kim, C.-G. Kim, S. Bhowmik, Improvement of tensile properties of CFRP composites under LEO space environment by applying MWNTs and thin-ply, Composites Part

【 A: Applied Science and Manufacturing 42 (6) (2011) 694-701. doi:10.1016/j.compositesa. 2011.02.011, URL http://linkinghub.elsevier.com/retrieve/pii/S1359835X11000558

[32] E. Miyazaki, M. Tagawa, K. Yokota, R. Yokota, Y. Kimoto, J. Ishizawa, Investigation into tolerance of polysiloxane-block-polyimide film against atomic oxygen, Acta Astronautica 66 (56) (2010) 922-928. doi:10.1016/j . actaastro.2009.09.002 URL http://linkinghub.elsevier.com/retrieve/pii/S009457650900441X

[33] H. Sirin, M. Kodal, B. Karaagac, G. Ozkoc, Effects of octamaleamic acid-POSS used as the adhesion enhancer on the properties of silicone rubber/silica nanocomposites, Composites Part B: Engineering 98 (2016) 370-381. doi:10.1016/j.compositesb.2016.05.024.

URL http://dx.doi.org/10.1016/j.compositesb.2016.05.024

[34] F. Constantin, S. A. Gârea, H. Iovu, The influence of organic substituents of polyhedral oligo- 
B: Engineering 44 (1) (2013) 558-564. doi:10.1016/j.compositesb.2012.02.036.

URL http://dx.doi.org/10.1016/j.compositesb.2012.02.036

[35] E. S. A. Rashid, K. Ariffin, C. C. Kooi, H. M. Akil, Preparation and properties of POSS/epoxy

1] composites for electronic packaging applications, Materials and Design 30 (1) (2009) 1-8. doi:

430 $10.1016 / j$.matdes.2008.04.065. 